\title{
Impact of Synchronous Generator De-excitation Dynamics on the Protection in Marine DC Power Distribution Networks
}

S. Kim, S. N. Kim, and D. Dujic

This material is posted here with permission of the IEEE. Such permission of the IEEE does not in any way imply IEEE endorsement of any of EPFL's products or services. Internal or personal use of this material is permitted. However, permission to reprint / republish this material for advertising or promotional purposes or for creating new collective works for resale or redistribution must be obtained from the IEEE by writing to pubs-permissions@ieee. org. By choosing to view this document, you agree to all provisions of the copyright laws protecting it. 


\title{
Impact of Synchronous Generator De-excitation Dynamics on the Protection in Marine DC Power Distribution Networks
}

\author{
Seongil Kim, Student Member, IEEE, Soo-Nam Kim, and Drazen Dujic, Senior Member, IEEE
}

\begin{abstract}
This paper presents the characteristics of power supply protection in DC shipboard power systems utilising de-excitation of a synchronous generator, which have been used to achieve a breaker-less protection scheme. From state-of-the-art analyses on the de-excitation and the DC ship protection, the analytical expressions of a DC short-circuit fault are introduced with the consideration of the generator dynamics and the de-excitation. The rectifier protection, based on the analytical expression, is examined in terms of the peak fault current (or peak non-repetitive surge current) and the overloading capability (or limiting load integral) of the rectifier diodes. Finally, experimental DC short-circuit tests are conducted with the rectifier-generator system rated of $10 \mathrm{~kW}$ and $500 \mathrm{~V}_{\mathrm{DC}}$. With the test results, the analytical expression derived in the paper is verified and, more importantly, the characteristics of the DC fault behaviours are discussed for different fault resistance, DC-link capacitance and exciter response.
\end{abstract}

Index Terms-De-excitation, DC Micro Grid, Marine Power Distribution Networks, Protection Coordination, Shipboard Power Systems.

\section{INTRODUCTION}

Rapid growth in the DC systems for commercial vessels is imperative, to meet ship energy efficiency regulations for reducing greenhouse gas emissions, e.g., energy efficiency design index (EEDI) and/or ship energy efficiency management plan (SEEMP) [1], [2]. According to the EEDI as presented in Table I, by 2025 , newly constructed ships have to be designed to have $30 \%$ less energy consumption than those built in 2004.

As one of the promising solutions, a low-voltage DC (LVDC) solution has been employed in shipboard power systems (SPS) in commercial use, voltage levels of around $1 \mathrm{kV}$ and power rating with up to $20 \mathrm{MW}$ (Fig. 1) [3]-[8]. In order to minimise the electrical installation cost for these solutions, the use of costly solid-state DC switches is only limited to the bus-tie purpose, and the feeder and bus faults are protected by fuses and power supply protection, respectively [9]-[13]. One approach for the power supply protection to handle the

Manuscript received December 29, 2019; revised February 7, 2020; accepted February 26, 2020. (Corresponding author: Seongil Kim),

S. Kim and D. Dujic are with the Power Electronics Laboratory of École Polytechnique Fédérale de Lausanne (EPFL), CH-1015 Lausanne, Switzerland (telephone: +41 21693 3968, e-mail: seongil.kim@epfl.ch; drazen.dujic@epfl.ch).

S.-N. Kim is with the Hyundai Electric \& Energy Systems Research Centre, 16891 Yongin, Republic of Korea (e-mail: kimsoonam@hyundaielectric.com).
TABLE I: Reduction factors in percentage for EEDI [1].

\begin{tabular}{ccccc}
\hline \hline Ship Type & Phase 0 & Phase 1 & Phase 2 & Phase 3 \\
& $2013-2014$ & $2015-2019$ & $2020-2024$ & 2025 \\
\hline Bulk carrier & 0 & 10 & 20 & 30 \\
Gas carrier & 0 & 10 & 20 & 30 \\
Tanker & 0 & 10 & 20 & 30 \\
Container ship & 0 & 10 & 20 & 30 \\
General cargo ship & 0 & 10 & 15 & 30 \\
Refrigerated & 0 & 10 & 15 & 30 \\
cargo carrier & & 10 & 20 & 30 \\
Combination carrier & 0 & & & \\
\hline
\end{tabular}

fault current from the generator is based on de-excitation of a synchronous generator without AC circuit breakers between the generator and the rectifier [11], [12].

For the reliable power supply protection, the fault characteristics limited by the de-excitation have to be characterised for designing the DC protection scheme and dimensioning the rectifier. Hence, this paper presents the DC fault characteristics with the de-excitation protection for a 6-pulse diode rectifier fed by a synchronous generator not only by the developed analytical description, but also by the experimental studies.

The paper is divided into five sections. In section II, stateof-the-art analyses are provided for the LVDC SPS protection and the de-excitation. The analytical expressions are derived in three stages: DC short-circuit in diode rectifier, transients in generator and de-excitation of generator in section III. In

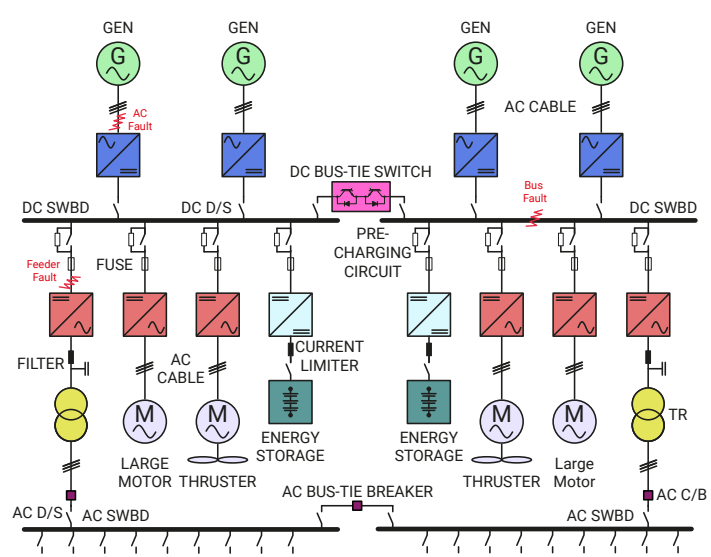

Fig. 1: Simplified schematic diagram of LVDC SPS. 
the same section, the rectifier protection is also discussed. Section IV presents the experimental tests of the de-excitation with the discussion of influences on fault resistance, DC-link capacitance and exciter response. The last section summaries the findings and the main results.

\section{State of the ART}

The current technologies, directly relevant for the main topic of the paper, are analysed into two parts: protection of LVDC ships, both commercially employed and academically proposed, and fast de-excitation for reducing the fault energy.

\section{A. Protection of Low-voltage DC SPS}

Since 2013, a three-level protection has been used as an economic solution for commercial LVDC vessels [9], [11], [12]. The three-level protection consists of three different fault controls which have different operating time frames (Fig. 2): fast action ( $1^{\text {st }}$ level) - bus separation with DC bus-tie switch based on solid-state technology $(10-40 \mu \mathrm{s})$, medium action $\left(2^{\text {nd }}\right.$ level) - feeder protection with high-speed fuse $(0.2-1 \mathrm{~ms})$ and slow action $\left(3^{\text {rd }}\right.$ level $)$ - power supply protection $(0.003-10 \mathrm{~s})$ [14].

For the power supply protection, several measures are available depending on rectifier type. In [15], an artificial short-circuit method is proposed for an active rectifier. This method blocks the fault current passing through the rectifier by providing low-impedance path artificially generated between the generator and the rectifier. In case of the thyristor rectifier, the fault current can be extinguished by changing the firing angle, e.g, $120^{\circ}$ called fold-back fault control [16]. To achieve faster fault current clearing, an active fold-back fault control is proposed by considering DC inductance, generator frequency and rectifier topology [17]. For the diode-based rectifier, the de-excitation combined with high subtransient reactance, specially designed to reduce the peak fault current, have been used to limit the fault current from the generator [11], [12]. This de-excitation measure is the main topic of the paper.

While [11], [12] provide the principle of the de-excitation and high sub-transient reactance with one experimental test result for diode overloading capability and fault energy, there is lack of information on analytical description, rectifier sizing

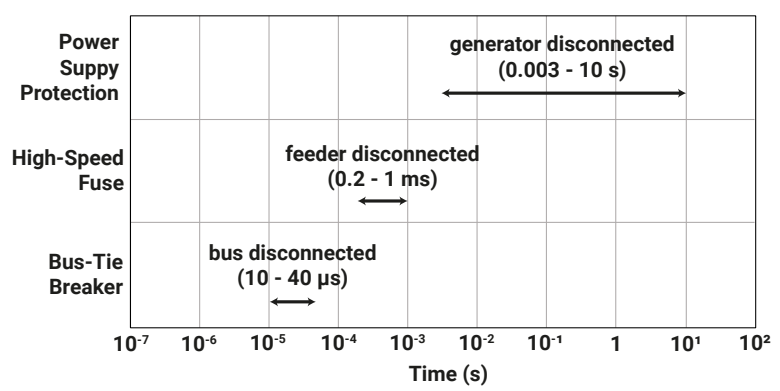

Fig. 2: Operating time frames of three-level protection for LVDC SPS [14]. Time discrimination in the three-level protection is coordinated with their different operating times and the time margins between the actions. (a)

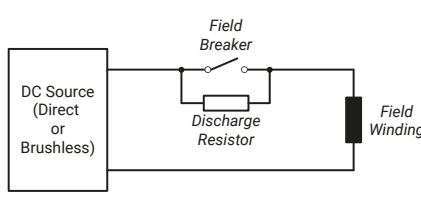

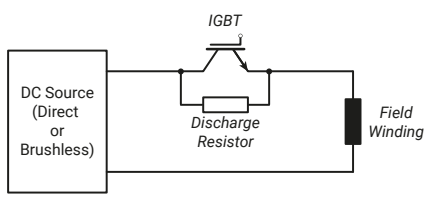

(b)
Fig. 3: Simplified schematic of fast field discharge circuits: (a) mechanical breaker and (b) IGBT [22].

and multiple system factor impact, e.g., fault resistance, DClink capacitance and exciter type (or exciter response). These technological gaps are covered by this paper with the analytical and experimental approaches.

\section{B. De-excitation of Synchronous Generator}

In conventional protection for AC systems, the de-excitation of a synchronous machine is considered as the loss of excitation fault and has to be protected by the generator protection system [18]. As the part of the generator protection, faster field discharging systems have been proposed in [19]-[21] and recommended in [22] to prevent machine damage from a severe fault in the vicinity of the machine or excitation system. While there are many fast discharge methods, the principal idea is to install the discharge resistor in the rotor circuit and to bypass the current flow through the resistor if the fast field discharge is needed, as shown in Fig. 3. This can be implemented by installation of the mechanical field breaker in parallel to the discharge resistor (Fig. 3a). For the quick operation, the mechanical breaker can be replaced by an insulated gate bipolar transistor (IGBT) (Fig. 3b).

It is analysed that the main focuses of [19]-[21] are limited to fast field suppression, discharge circuit topologies, discharge resistor selection and overvoltage management for brushless excitation systems. This is because brushless excitation systems have slower response (or higher time constant) compared to direct excitation systems.

On the other hand, the new system, which is an off-grid micro-grid system based on DC technology, opens the door to use the de-excitation as the protection method without any circuit breakers, as mentioned earlier. The fault current and its energy should be carefully managed in case that the de-excitation is used for the rectifier protection purpose in DC SPS due to very low overloading capability of the semiconductor compared to conventional AC equipment. Thus, the comprehensive fault behaviours with the de-excitation should be scrutinized into different system factors, as presented hereafter.

\section{Derivation of Analytical Expression}

The fault current under the de-excitation in DC SPS, which is a weak-grid system with a low short-circuit ratio, is composed of different system dynamics. To effectively describe its behaviour, the analytical expression is presented in three dynamics stages. Moreover, the rectifier sizing is discussed with the analytical expression introduced. 


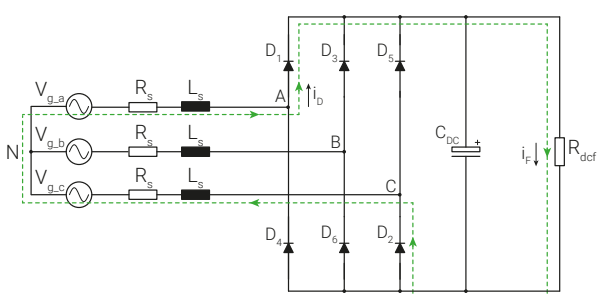

(a)

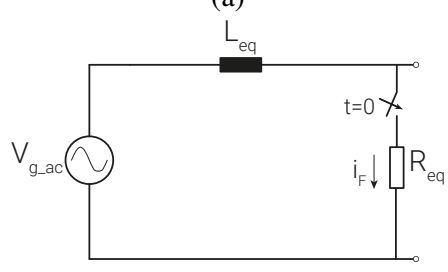

(b)

Fig. 4: Equivalent circuits of a 6-pulse diode rectifier under a DC fault: (a) current flow for one positive half cycle and (b) a simple R-L expression.

\section{A. DC Short-Circuit in 6-Pulse Diode Rectifier}

When a DC short-circuit fault occurs in a 6-pulse diode rectifier fed by a three-phase source, the fault current is conducted through one of the diodes in the positive rail $\left(D_{1}\right.$, $D_{3}$ and $\left.D_{5}\right)$ and one of the diodes in the negative rail $\left(D_{2}\right.$, $D_{4}$ and $D_{6}$ ) as shown in Fig. 4a. Each diode conducts the fault current with the interval angle of $120^{\circ}$. For the maximum fault current condition $\left(R_{d c f}=0\right)$ which allows for neglecting $C_{D C}$, the system can, therefore, be expressed as a simple R-L circuit (Fig. 4b). For this simple circuit, when $D_{1}$ is conducting, and the current passing through $D_{1}\left(i_{D}\right)$ is [23]:

$$
i_{D}(t)=\frac{V_{m}}{Z} \sin (\omega t+\alpha-\phi)-\frac{V_{m}}{Z} \sin (\alpha-\phi) e^{-\frac{R_{e q}}{L_{e q}} t}
$$

where $V_{g_{-} a c}=V_{m} \sin (\omega t+\alpha), R_{e q}=2 R_{S}, L_{e q}=2 L_{S}$, $Z=\sqrt{R_{e q}^{2}+\left(\omega L_{e q}\right)^{2}}$, and $\phi=\arctan \left(\frac{\omega L_{e q}}{R_{e q}}\right)$. In Eq. (1) the fault current consists of the steady-state current and the DC component. Depending on the instant of the short-circuit, the current only consists of the steady-state current (zero DC component) when $\alpha=\phi$ or can theoretically reach $2 V_{m} / Z$ with the maximum DC component of $V_{m} / Z$ when $\alpha=\phi-$ $\pi / 2$.

\section{B. Transient Phenomena in Synchronous Generator}

However, Eq. (1) is only valid for a power system with a high short-circuit capacity. In reality, the dynamics of the generator should be considered for transient analyses, especially in case of an off-grid system directly powered by the generator like SPS. Under the short-circuit condition, the simplified model of the generator (Fig. 5) is based on the effective direct axis (d-axis) reactance due to the lagging current by almost $90^{\circ}$ with respect to the field voltage [24]. This effective reactance varies in three stages with their time constants: subtransient reactance $\left(X_{d}^{\prime \prime}\right)$ and time constant $\left(T_{d}^{\prime \prime}\right)$, transient reactance $\left(X_{d}^{\prime}\right)$ and time constant $\left(T_{d}^{\prime}\right)$, and reactance $\left(X_{d}\right)$. In addition, the decay of the DC component is decided by the average

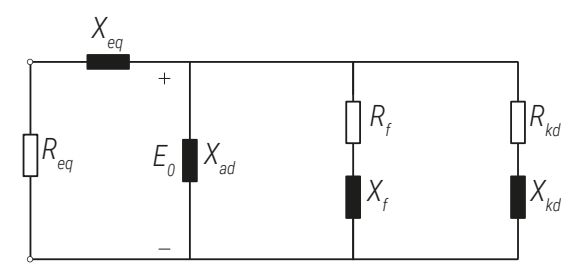

(a)

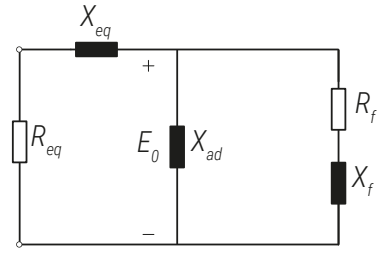

(b)

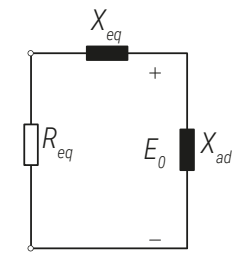

(c)
Fig. 5: Equivalent circuits of a d-axis synchronous generator: (a) subtransient, (b) transient and (c) steady-state.

value of subtransient d-axis reactance and quadrant-axis (qaxis) reactance $\left(X_{q}^{\prime \prime}\right)$ and the stator winding resistance $\left(R_{a}\right)$ [6]. The fault current under the consideration of the generator dynamics is:

$$
\begin{aligned}
i_{D}(t)= & \sqrt{2} E_{0} Y(t) \sin (\omega t+\alpha-\phi) \\
& +\frac{\sqrt{2} E_{0}}{\sqrt{R_{e q}{ }^{2}+X_{d}^{\prime \prime 2}}} \sin (\alpha-\phi) e^{-\frac{t}{T_{a}}}
\end{aligned}
$$

where, $Y(t)=\left(\frac{1}{\sqrt{R_{e q}{ }^{2}+X_{d}^{\prime 2}}}-\frac{1}{\sqrt{R_{e q}{ }^{2}+X_{d}^{\prime 2}}}\right) e^{-\frac{t}{T_{d}^{\prime \prime}}}+$ $\left(\frac{1}{\sqrt{R_{e q}{ }^{2}+X_{d}^{\prime 2}}}-\frac{1}{\sqrt{R_{e q}^{2}+X_{d}^{2}}}\right) e^{-\frac{t}{T_{d}^{\prime}}}+\frac{1}{\sqrt{R_{e q}^{2}+X_{d}^{2}}}$ and the parameters of $Y(t)$ are provided in Appendix.

Note that Eq. (2) is the same as the fault current equation in [24], [25], widely used for the maximum fault current calculation, if $R_{e q}=0$.

\section{De-excitation of Synchronous Generator}

Direct and brushless excitation systems (Fig. 6), which govern the dynamic response of the generator, have been widely used for marine applications. While the direct excitation system has fast dynamic response, the brushless excitation system takes longer time to completely remove the excitation due to its indirect DC voltage generation as well as its inability to reverse the voltage applied to the rotor winding. Once the de-excitation is started, the internal stator voltage $\left(E_{0}\right)$ is not constant. Thus, in Eq. (2), the internal voltage decrease in time should be considered to calculate more accurately fault current. This phenomenon and the full analytical expression are described hereafter.

During the de-excitation of the excitation systems, the main exciter field voltage changes from its initial voltage $\left(V_{f 0}\right)$ to 


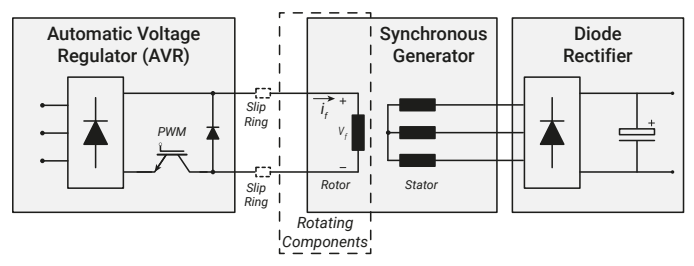

(a)

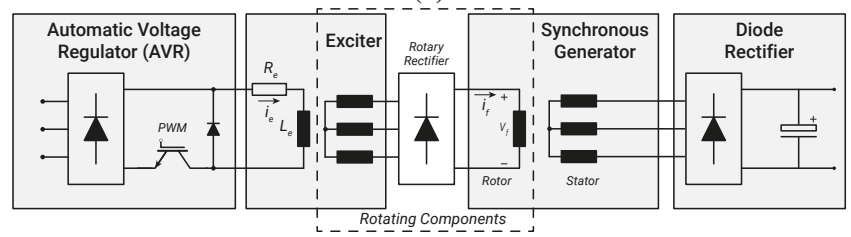

(b)

Fig. 6: One-quadrant AVR combined with synchronous generator and diode rectifier: (a) direct excitation and (b) brushless excitation.

zero with the time constant of the exciter $\left(T_{e}\right)$. Thus, the change in the field voltage in S-domain can be expressed as:

$$
\Delta V_{f}(s)=\frac{1}{1+s T_{e}} \frac{V_{f 0}}{s}
$$

Ideally, the time constant for the exciter should be zero for the direct excitation system, but it is not allowed to avoid the overvoltage in the circuit and the AVR has the ramp rate limitation in practice [26]. The time constant should be, therefore, considered for the brushless excitation as well as for the direct excitation.

From the d-axis equivalent circuit shown in Fig. 7, the incremental field current $\left(I_{f}\right)$ during the short-circuit according to the change in the field voltage is:

$$
\Delta I_{f}(s)=\frac{\Delta V_{f}(s)}{R_{f}+s\left(\frac{X_{a d} X_{e q}}{X_{a d}+X_{e q}}\right)}=\frac{1}{1+s T_{d}^{\prime}} \frac{\Delta V_{f}(s)}{R_{f}}
$$

As shown in Fig. 7, the relationship between the field current and the d-axis current is:

$$
\begin{aligned}
\Delta I_{d}(s) & =\frac{X_{a d}}{\sqrt{R_{e q}^{2}+\left(X_{e q}+X_{a d}\right)^{2}}} \Delta I_{f}(s) \\
& =\frac{X_{a d}}{\sqrt{R_{e q}^{2}+X_{d}^{2}}} \Delta I_{f}(s)
\end{aligned}
$$

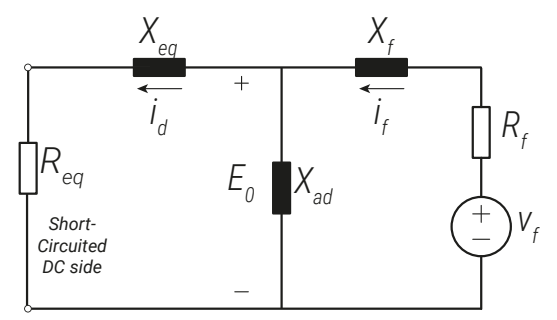

Fig. 7: D-axis equivalent circuit with short-circuited stator and field voltage.
By combining (3), (4) and (5), the change in the d-axis current in time domain is:

$$
\begin{aligned}
\Delta I_{d}(s) & =(1-F(t)) \frac{X_{a d}}{\sqrt{R_{e q}^{2}+X_{d}^{2}}} \frac{V_{f 0}}{R_{f}} \\
& =(1-F(t)) \frac{E_{0}}{\sqrt{R_{e q}^{2}+X_{d}^{2}}}
\end{aligned}
$$

where, $F(t)=\frac{T_{d}^{\prime} e^{-t / T_{d}^{\prime}}-T_{e} e^{-t / T_{e}}}{T_{d}^{\prime}-T_{e}}$

Eq. (6) shows that the change in the d-axis current during the de-excitation is the function of $F(t)$ and thus, by considering this function to the internal stator voltage, the fault current from the source is:

$$
\begin{aligned}
i_{D}(t)= & \sqrt{2} E_{0} Y(t) F(t) \sin (\omega t+\alpha-\phi) \\
& +\frac{\sqrt{2} E_{0}}{\sqrt{R_{e q}^{2}+X_{d}^{\prime \prime 2}}} \sin (\alpha-\phi) e^{-\frac{t}{T_{a}}}
\end{aligned}
$$

As mentioned earlier, the fault current flows from the positive rail to the negative rail with the one-third phase interval in case of the 6-pulse rectifier. Thus, by removing the sinusoidal term in Eq. (7), the DC fault current $\left(i_{F}\right)$ can be finally expressed as:

$$
i_{F}(t)=\sqrt{2} E_{0}\left(Y(t) F(t)+\frac{\sin (\alpha-\phi)}{\sqrt{R_{e q}^{2}+X_{d}^{\prime 2}}} e^{-\frac{t}{T_{a}}}\right)
$$

\section{Discussion on Rectifier Sizing}

During the conduction of one of the diodes, the peak current passing through the diode $\left(i_{\text {Dpeak }}\right)$, which is the current from the generator as mentioned, is equal to the peak current $\left(i_{\text {Fpeak }}\right)$ when $\alpha-\phi=\pi / 2$ and $t=0$ in Eq. (8). Hence, the peak non-repetitive surge current of diodes $\left(I_{F S M}\right)$ should be sized to sustain the peak fault current as:

$$
\begin{aligned}
I_{F S M}>i_{\text {Dpeak }} & =i_{\text {Fpeak }} \\
& =\frac{\sqrt{2} E_{0}}{\sqrt{R_{e q}^{2}+X_{d}^{\prime \prime 2}}}\left(1+\frac{X_{d}^{\prime \prime}}{\sqrt{R_{e q}^{2}+X_{d}^{\prime \prime 2}}}\right)
\end{aligned}
$$

By considering the worst condition $\left(R_{e q}=0\right)$ in Eq. (9), the diode should sustain the maximum current, $i_{\text {Fpeak-max }}=$ $2 \sqrt{2} E_{0} / X_{d}^{\prime \prime}$.

In case of the 6-pulse rectifier, the amount of the energy passing through each diode is one-third of the energy of the DC fault current $\left(I^{2} t_{F}\right)$ due to the conduction interval. In addition, the time delay $\left(T_{d}\right)$ adds the latency of the deexcitation. With these considerations, the diode has to have higher overloading capability $\left(I^{2} t_{D}\right)$ than one-third of the maximum fault current energy $(\phi=\pi / 2)$ with the time delay as: 


$$
\begin{aligned}
& I^{2} t_{D}>\frac{1}{3} \int_{0}^{\infty} i_{F}^{2}(t) d t= \\
& \frac{2}{3} E_{0}{ }^{2} \int_{0}^{T_{d}}\left\{Y(t)+\frac{1}{\sqrt{R_{e q}{ }^{2}+X_{d}^{\prime \prime 2}}} e^{-\frac{t}{T_{a}}}\right\}^{2} d t+ \\
& \quad \frac{2}{3} E_{0}{ }^{2} \int_{T_{d}}^{\infty}\left\{Y(t) F\left(t-t_{d}\right)+\frac{1}{\sqrt{R_{e q}{ }^{2}+X_{d}^{\prime \prime 2}}} e^{-\frac{t}{T_{a}}}\right\}^{2} d t
\end{aligned}
$$

If the fault stresses are kept within the diode ratings specified in the datasheet, the diodes will remain operational after experiencing fault event. This implies that the diodes can sustain a large number of the faults, if the diodes are properly selected and thermal conditions are favorable (diodes are cooled down after the fault, and before the new fault event).

\section{EXPERIMENTAL TESTS}

In order to verify the analytical expression and characterise the fault behaviours under the de-excitation, the experimental tests are conducted with the laboratory setup.

\section{A. Test Setup}

Test setup rated for $10 \mathrm{~kW}$ and $500 \mathrm{~V}_{\mathrm{DC}}$ consists of a DC motor drive, a synchronous generator, a 6-pulse diode rectifier with DC link capacitors and resistors, as shown in Fig. 8. The generator, available in the laboratory, has no damping winding (neglecting the subtransient) and is based on the direct excitation and, therefore, the brushless excitation dynamics is emulated by a programmable logic controller (PLC) (Fig. 8a). When the de-excitation is commanded, the PLC controls AVR output voltages with respect to given time constants.

As mentioned earlier, although the direct excitation system has fast response, it cannot immediately remove the excitation due to the AVR protection. Thus, the fastest excitation removal is tested and the time constant of $0.1 \mathrm{~s}\left(T_{e}=0.1 \mathrm{~s}\right)$ is observed from the test result in Fig. 9. $T_{e}=1.0 \mathrm{~s}$ is taken into account for the brushless excitation system. The excitation responses, which are commended to turn-off immediately for the direct excitation and to regulate the excitation current with the time constant of $1.0 \mathrm{~s}$ for the brushless excitation, are shown in Fig. 9.

There is a time delay associated with activating the deexcitation due to fault detection, post-processing, protection coordination, and so on. This time delay $\left(T_{d}\right)$ is also replicated by the PLC.

\section{B. DC Fault Behaviour}

The DC short-circuit tests are performed in the test setup with the condition of $C_{D C}=2.3 \mathrm{mF}$ and $R_{F}=0.9 \Omega$. In Fig. 10 , general DC fault behaviours are seen considering that the DC fault current is composed of the current from the DC link capacitor with the maximum amplitude of $V_{D C} / R_{e q}$, mainly contributing to the first peak, and the current contribution from the generator, which is important for the rectifier protection

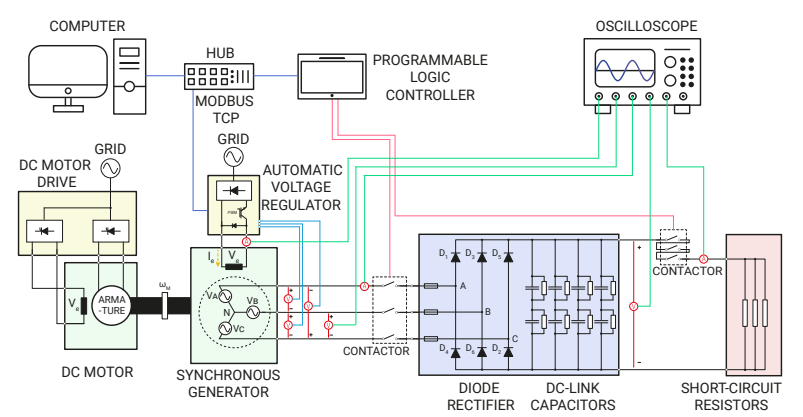

(a)

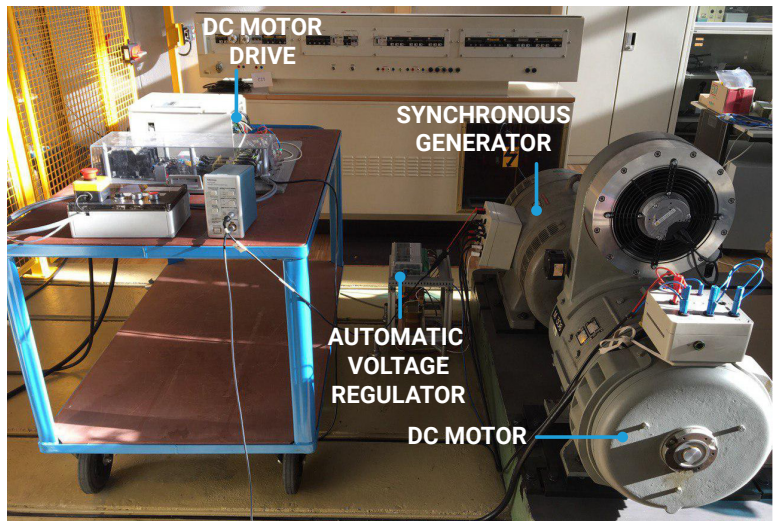

(b)

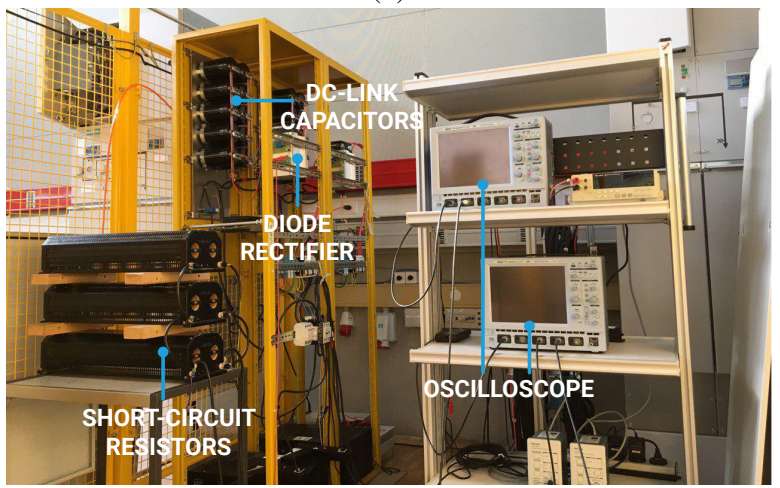

(c)

Fig. 8: Experimental test setup: (a) principal schematic, (b) actual implementation - generator side and (c) actual implementation - rectifier and load side.

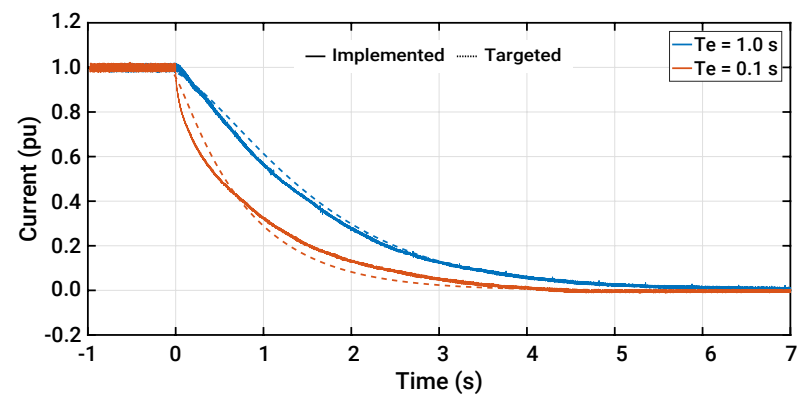

Fig. 9: Implemented excitation responses for direct (blue, $T e=0.1 \mathrm{~s})$ and brushless excitation systems (red, $T e=1.0 \mathrm{~s})$. 

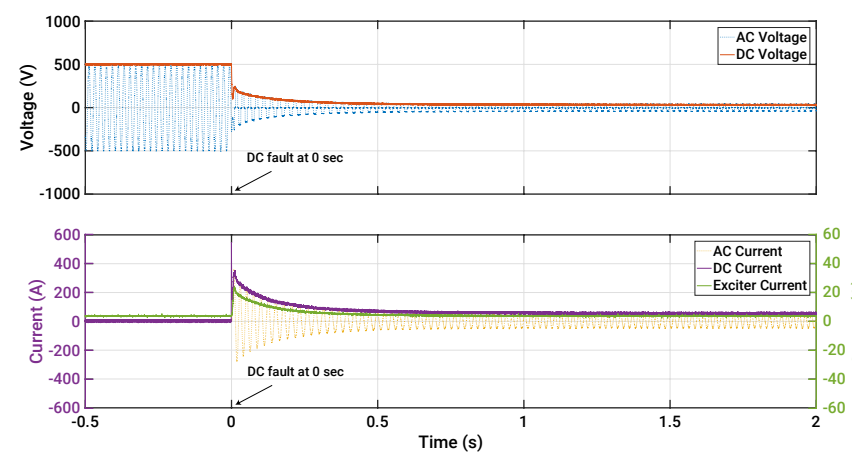

(a)
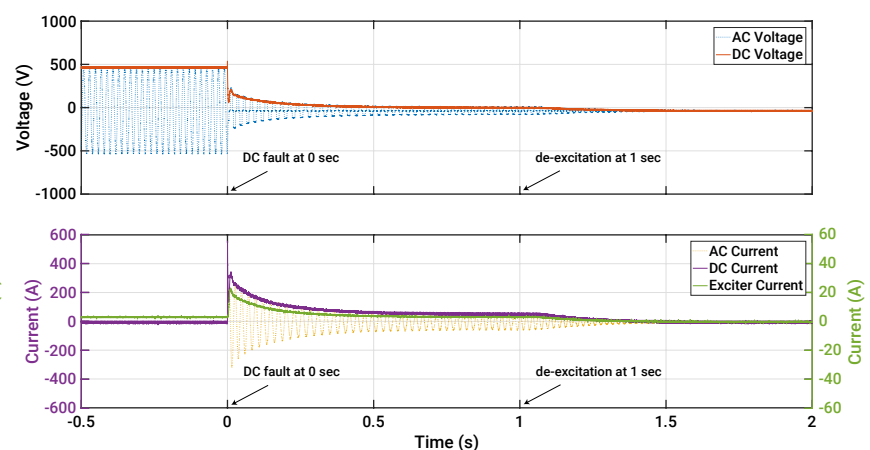

(b)

Fig. 10: DC short-circuit behaviours: (a) without de-excitation and (b) with de-excitation.

TABLE II: Parameters for DC short-circuit current calculation.

\begin{tabular}{cccc}
\hline \hline Parameter & Symbol & Case 1 & Case 2 \\
\hline $\begin{array}{c}\text { Applied voltage } \\
\text { Generator }\end{array}$ & $\sqrt{2} E_{0}$ & 500 & 500 \\
$\begin{array}{c}\text { transient } \\
\text { De-excitation }\end{array}$ & $F(t)$ & $\left(\frac{1}{\sqrt{0.9^{2}+1.1^{2}}}-\frac{1}{\sqrt{0.9^{2}+9.8^{2}}}\right) e^{-\frac{t}{0.118}}+\frac{1}{\sqrt{0.9^{2}+9.8^{2}}}$ & $\left(\frac{1}{\sqrt{1.3^{2}+1.1^{2}}}-\frac{1}{\sqrt{1.3^{2}+9.8^{2}}}\right) e^{-\frac{t}{0.135}+\frac{1}{\sqrt{1.3^{2}+9.8^{2}}}}$ \\
\hline \hline
\end{tabular}

and can be recognised from the second peak in the DC fault current. On another point, the AC and DC currents are initially very high due to low transient reactance and turn into the steady-state with the reactance in this stage.

Similar to the current, the DC voltage is firstly dropped with the function of capacitance and inductance values, and then the $\mathrm{DC}$ voltage is decided by the positive peak $\mathrm{AC}$ voltage varied with the generator dynamics. As mentioned earlier, the direct excitation system is used for the test. Hence, in the setup, the field current is the same as the exciter current and its transient behaviour is a linear function of the fault current (the d-axis current) as shown in Fig. 10 and described in Eq. (5).

Furthermore, the effect of the de-excitation is investigated by conducting the DC short-circuit tests without and with the de-excitation. Although there is the steady-state short-circuit current without the de-excitation protection (Fig. 10a), the current diminishes in time and then goes to zero with the protection by the de-excitation (Fig. 10b).

\section{Verification of Analytical Expression}

In order to verify the analytical expression, the DC fault currents and energies tested are compared with the calculated values by Eq. (9) and Eq. (10). Two results are shown in Fig. 11: Case 1 (Fig. 11a) $-R_{F}=0.9 \Omega$ (fault resistance), $T_{d}=$ $1.0 \mathrm{~s}$ (de-excitation time delay) and $T_{e}=0.1 \mathrm{~s}$ (exciter time constant) and Case 2 (Fig. 11b) $-R_{F}=1.3 \Omega, T_{d}=1.0 \mathrm{~s}$ and $T_{e}=1.0 \mathrm{~s}$. The parameters for the analytical equations are shown in Table II.

In the analytical expression introduced, the first peak of the DC current is not considered and this makes some deviation between them. However, this does not represent a big issue in terms of the energy passing through the rectifier due to its very short duration. Rather than this, it is observed that the current deviation during the subtransient and transient periods develops the bigger energy difference because the deviation is squared and integrated in time.

The comparison shows that although there are certain differ-

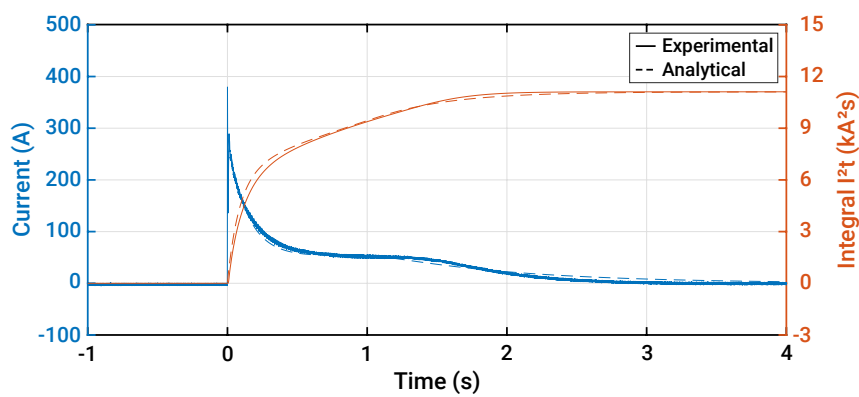

(a)

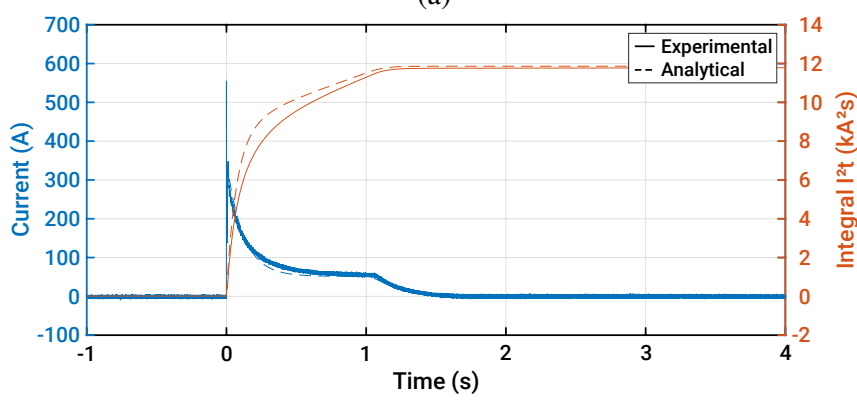

(b)

Fig. 11: Comparison of fault current and its energy between experimental results and analytical values calculated by Eq. (8): (a) Case 1 and (b) Case 2. 
ences in the fault current and, more noticeably, in the energy, the equations introduced are reasonably matching with the test results. Hence, the equations could be used for the rectifier sizing and protection purpose.

\section{Influence on Fault Resistance}

The DC line-to-line short-circuit includes certain value of fault resistance which is a function of the arc length and circuit current [27]. Thus, the DC fault can occur with different fault resistance values depending system condition. For the investigation of the fault resistance influence, the DC shortcircuit tests are conducted with four different fault resistance by combining the three resistors in Fig. $8 \mathrm{c}$ in series or parallel: $4.8 \Omega, 2.5 \Omega, 1.3 \Omega$ and $0.9 \Omega$. The test results show that low fault resistance develops high voltage drop and high AC/DC fault current, as expected (Fig. 12).

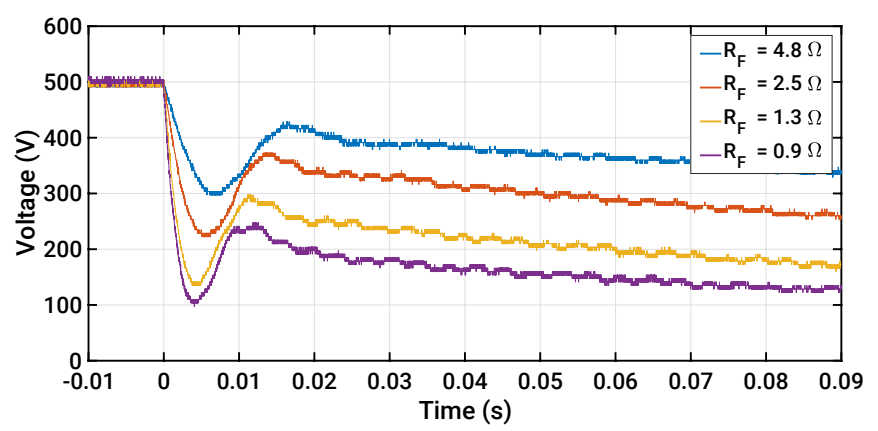

(a)

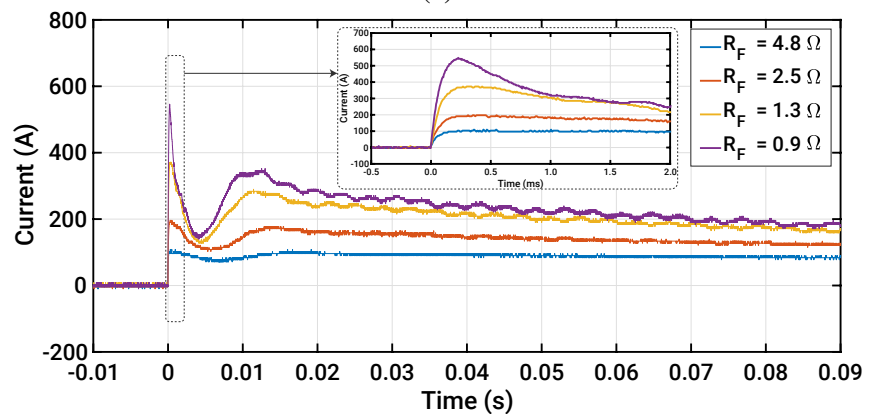

(b)

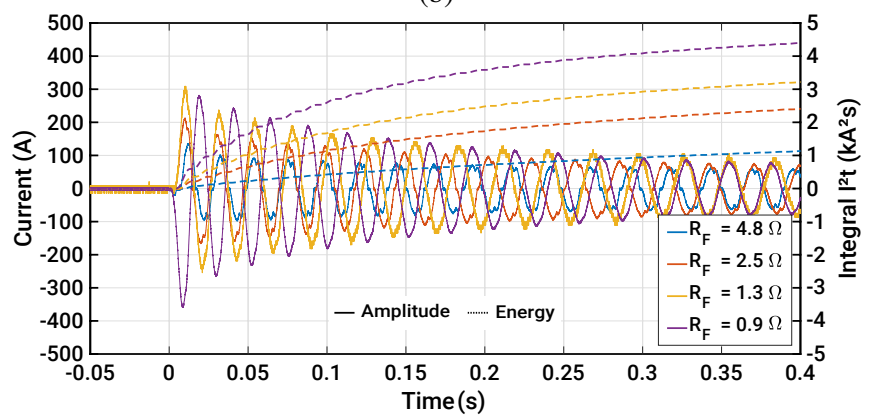

(c)

Fig. 12: Fault behaviours under different fault resistance: (a) DC voltages, (b) DC currents and (c) AC currents. The zoomed figure for the initial DC currents is provided in Fig. 12b.

\section{E. Influence on DC-link Capacitance}

The DC-link capacitor, which is a part of the rectifier, not only helps to mitigate the voltage ripple, but also plays a role of the inertia in the DC system. The capacitor values are different with system voltage, power rating, requirement, control, and so on. In order to examine the effect on the capacitor value, DC short-circuit tests are carried out with four capacitor values by connecting or disconnecting the capacitors in Fig. $8 \mathrm{c}$ : $2.3 \mathrm{mF}, 4.6 \mathrm{mF}, 6.9 \mathrm{mF}$ and $9.2 \mathrm{mF}$.

The test results show that the higher capacitor value comes with lower voltage drop and higher DC fault current (Fig. 13a and Fig. 13b), as expected. Otherwise, the amplitude AC fault is hard to compare because its first peak is dependent on the instant of the short-circuit making. For the further discussion, the energies for the four conditions are calculated from the measured data and compared in Fig. 13c. This comparison

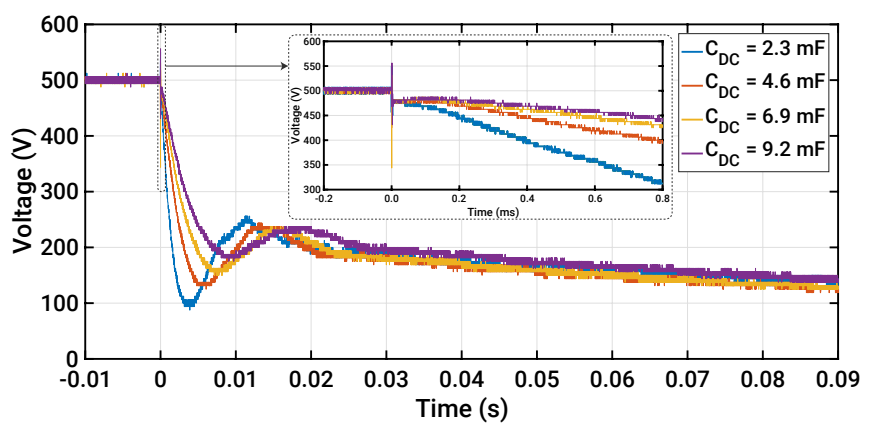

(a)

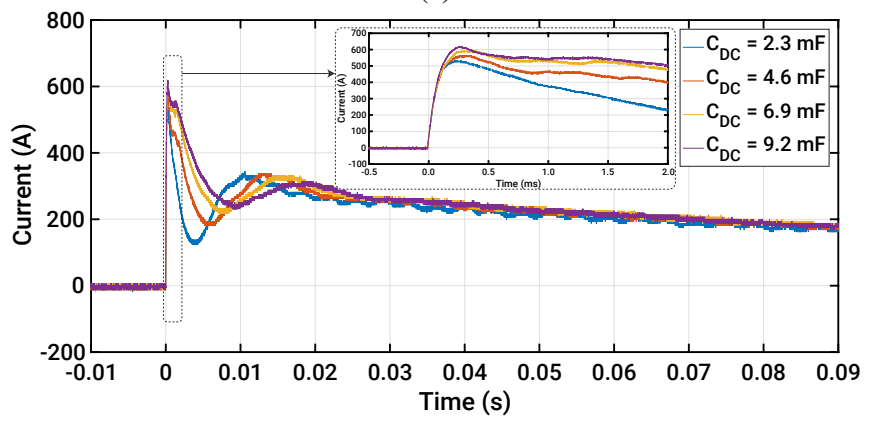

(b)

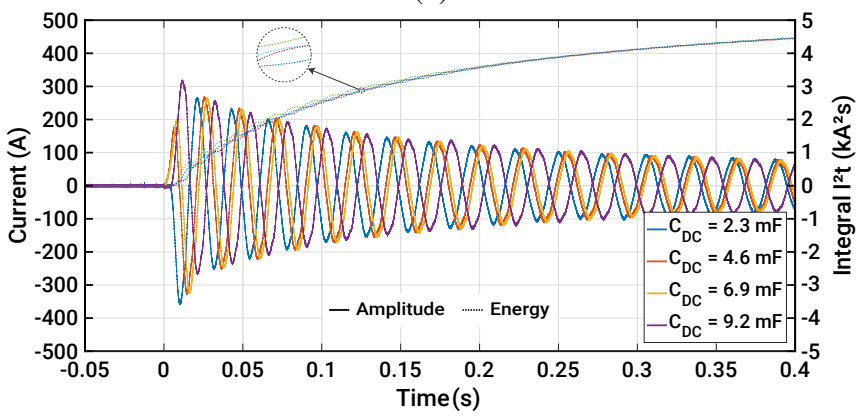

(c)

Fig. 13: Fault behaviours under different capacitance: (a) DC voltages, (b) DC currents and (c) AC currents. The zoomed figures are provided in each figure: in Fig. 13a - initial DC voltage drops, in Fig. 13b - initial DC currents and in Fig. 13c - different fault energies. 
gives an important information. The influence on the capacitor value is small enough to be negligible in terms of the fault energy passing through the rectifier. Thus, while capacitor banks installed in the DC SPS have direct impact on the developed short circuit current peaks, they are not crucial element for rectifier sizing (e.g., diode selection is the analysed case).

\section{F. Influence on Exciter Response}

Depending on exciter type, the de-excitation characteristics are different. In the study, the direct and brushless excitation systems are analysed with the different exciter time response implemented by the PLC: $T_{e}=0.1 \mathrm{~s}$ for the direct excitation and $T_{e}=1.0 \mathrm{~s}$ for the brushless excitation. Moreover, the time delay associated with the de-excitation activation is studied with different time delay: $0 \mathrm{~s}, 0.5 \mathrm{~s}, 1.0 \mathrm{~s}$. For the comparison purpose, no de-excitation results are added in Fig. 14.

When the de-excitation is activated, the rate of rise of fault energy becomes lower with its time constant. In the study, The fault energies are $11.8 \mathrm{kA}^{2} \mathrm{t}$ and $12.9 \mathrm{kA}^{2} \mathrm{t}$ for the direct and brushless excitation systems, respectively. This implies that the rectifier for the brushless excitation should have around $10 \%$ higher overloading capability than the direct excitation in the study condition.

The time delay is also an important factor to increase the fault energy. The less time delay allows to aid to mitigate the fault energy, as shown in Fig. 14b. Hence, this time delay should be considered for the design of protection schemes and rectifier sizing, as described in Eq. (10).

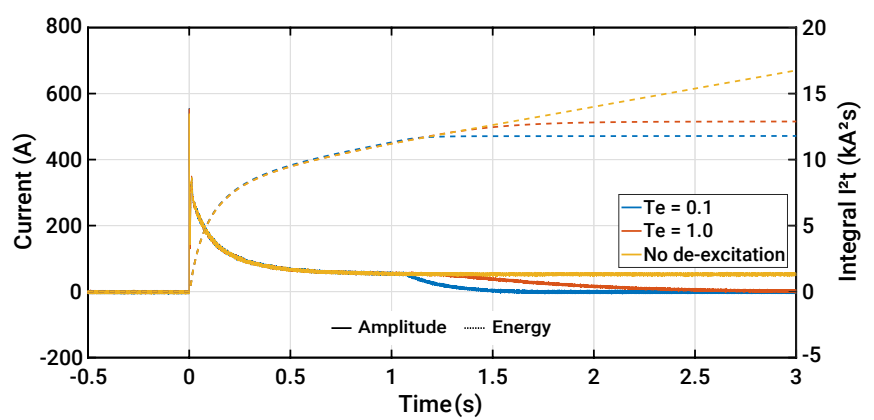

(a)

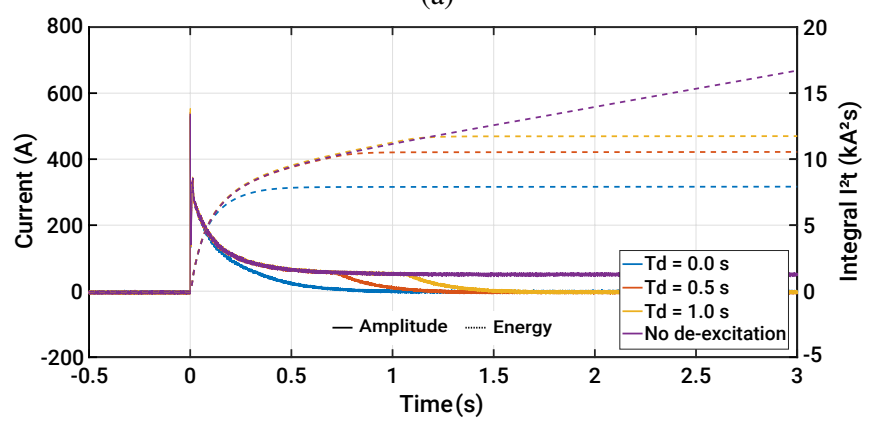

(b)

Fig. 14: Fault behaviours under different exciter response: (a) exciter time constant and (b) time delay to be taken to activate de-excitation after fault instant.

\section{CONCLUSION}

This paper has presented the comprehensive study results on the protection method by the de-excitation of the generator combined with the diode rectifier. The analytical expressions for the de-excitation are introduced and, from the analytical expression, the rectifier sizing is discussed in terms of the peak fault current and its energy. The experimental tests are carried out and discussed for different fault resistance, DC-link capacitance and exciter response.

The DC fault characteristics and analytical expressions under the de-excitation, which are described with the consideration of the generator dynamics and the de-excitation, are verified with the test results. This implies that the introduced analytical equation can be used for developing the protection scheme and dimensioning the rectifier.

The experimental test results show that the protection method by the de-excitation has to consider the system factors, e.g., DC fault resistance, exciter type and de-excitation delay time. On the other hand, the capacitor banks only have direct impact on the developed DC fault current peak and they are not crucial elements for the rectifier sizing.

\section{APPENDIX}

The parameters for $Y(t)$ in Eq. (2) are:

$$
\begin{aligned}
X_{d}= & X_{e q}+X_{a d}, \\
X_{d}^{\prime}= & X_{e q}+\left(\frac{1}{X_{a d}}+\frac{1}{X_{f}}\right)^{-1}, \\
X_{d}^{\prime \prime}= & X_{e q}+\left(\frac{1}{X_{a d}}+\frac{1}{X_{f}}+\frac{1}{X_{k d}}\right)^{-1}, \\
T_{a}= & \frac{X_{d}^{\prime \prime}+X_{q}^{\prime \prime}}{2 R_{e q}} \\
T_{d}^{\prime}= & \left.\frac{1}{\omega R_{f}}\left(X_{f}+\left(\frac{1}{X_{e q}}+\frac{1}{X_{a d}}\right)^{-1}\right)^{-1}\right), \text { and } \\
& +\frac{1}{\omega R_{e q}}\left(X_{e q}+\left(\frac{1}{X_{f}}+\frac{1}{X_{a d}}\right)^{-1}\right) \\
T_{d}^{\prime \prime}= & \frac{1}{\omega R_{k d}}\left(X_{k d}+\left(\frac{1}{X_{e q}}+\frac{1}{X_{a d}}+\frac{1}{X_{f}}\right)^{-1}\right) \\
& +\frac{1}{\omega R_{e q}}\left(X_{e q}+\left(\frac{1}{X_{k d}}+\frac{1}{X_{a d}}+\frac{1}{X_{f}}\right)^{-1}\right)
\end{aligned}
$$

\section{REFERENCES}

[1] "International Convention for the Prevention of Pollution from Ships (MARPOL)," Resolution MEPC.203(62), pp. 1-19, Jul. 2011.

[2] O. Alnes, S. Eriksen, and B. Vartdal, "Battery-powered ships: A class society perspective," IEEE Electrification Magazine, vol. 5, no. 3, pp. 10-21, Sep. 2017.

[3] "Onboard DC Grid Technology," Available: https://new.abb.com/marine/marine/systems-and-solutions/powergeneration-and-distribution/onboard-dc-grid [Accessed: Dec. 16, 2019].

[4] "Innovative diesel-electric propulsion systems," Available: https://new.siemens.com/global/en/markets/marine/electric-propulsionand-drives.html [Accessed: Dec. 16, 2019]. 
[5] "High efficiency, integrated compact power system for electric propulsion vessels," Available: https://www.ingeteam.com/ [Accessed: Dec. 16, 2019].

[6] "Hybrid DC machinery," Available: http://wetech.fi/solutions/solutionfive/ [Accessed: Dec. 16, 2019].

[7] K. Satpathi, V. M. Balijepalli, and A. Ukil, "Modeling and real-time scheduling of dc platform supply vessel for fuel efficient operation,' IEEE Transactions on Transportation Electrification, vol. 3, no. 3, pp. 762-778, Sep. 2017.

[8] J. J. Valera-Garcia and I. Atutxa-Lekue, "On the optimal design of hybrid-electric power systems for offshore vessels," IEEE Transactions on Transportation Electrification, vol. 5, no. 1, pp. 324-334, Mar. 2019.

[9] J. F. Hansen, J. O. Lindtjørn, and K. Vanska, "Onboard DC Grid for enhanced DP operation in ships," in Dynamic Positioning Conference, Houston, 2011.

[10] J. F. Hansen, F. Wendt, and J. O. Lindtjørn, "Fuel efficient power plant featuring variable speed generation system for DP drilling units," in Dynamic Positioning Conference, Houston, pp. 1-13, Oct. 2016.

[11] S. O. Settemsdal, E. Haugan, K. Aagesen, and B. Zahedi, "New Enhanced Safety Power Plant Solution for DP Vessels Operated in Closed Ring configuration," in Dynamic Positioning Conference, Houston, 2014.

[12] E. Haugan, H. Rygg, A. Skjellnes, and L. Barstad, "Discrimination in offshore and marine dc distribution systems," in 2016 IEEE 17th Workshop on Control and Modeling for Power Electronics (COMPEL), pp. 1-7, Jun. 2016.

[13] S. Lee, Y. Son, H. Cho, S. Sul, S. Kim, N. Kang, and W. Park, "Simplified thermal model of semiconductor fuse for dc distribution system," in 2019 10th International Conference on Power Electronics and ECCE Asia (ICPE 2019 - ECCE Asia), pp. 2641-2646, May. 2019.

[14] S. Kim, S. Kim, and D. Dujic, "Extending protection selectivity in dc shipboard power systems by means of additional bus capacitance," IEEE Transactions on Industrial Electronics, vol. 67, no. 5, pp. 3673-3683, May. 2020

[15] S. Kim, D. Dujic, and S. Kim, "Protection schemes in low-voltage DC shipboard power systems," in PCIM Europe 2018; International
Exhibition and Conference for Power Electronics, Intelligent Motion Renewable Energy and Energy Management, pp. 1-7, Jun. 2018.

[16] D. Jovcic and K. Ahmed, High Voltage Direct Current Transmission. Converters, Systems and DC Grids. John Wiley \& Sons, Limited, 2015.

[17] D. Dong, Y. Pan, R. Lai, X. Wu, and K. Weeber, "Active fault-current foldback control in thyristor rectifier for dc shipboard electrical system," IEEE Journal of Emerging and Selected Topics in Power Electronics, vol. 5, no. 1, pp. 203-212, Mar. 2017.

[18] W. A. Elmore, Protective Relaying: Theory and Applications. CRC press, 2003.

[19] C. A. Platero, M. Redondo, F. Blazquez, and P. Frias, "High-speed deexcitation system for brushless synchronous machines," IET Electric Power Applications, vol. 6, no. 3, pp. 156-161, Mar. 2012.

[20] E. Rebollo, F. R. Blanquez, C. A. Platero, F. Blazquez, and M. Redondo, "Improved high-speed de-excitation system for brushless synchronous machines tested on a 20 mva hydro-generator," IET Electric Power Applications, vol. 9, no. 6, pp. 405-411, 2015.

[21] E. Rebollo, C. A. Platero, F. Blazquez, and R. Granizo, "Internal sudden short-circuit response of a new hsbds for brushless synchronous machines tested on a 15 mva generator," IET Electric Power Applications, vol. 11, no. 4, pp. 495-503, 2017.

[22] "Ieee recommended practice for the specification and design of field discharge equipment for synchronous machines," IEEE Std 421.6-2017, pp. 1-38, Jun. 2017.

[23] P. Kundur, N. Balu, and M. Lauby, Power System Stability and Control, ser. EPRI power system engineering series. McGraw-Hill Education, 1994

[24] H. Saadat, Power System Analysis. McGraw-Hill, 2009.

[25] "IEC 60909-0:2016 Short-circuit currents in three-phase a.c. systems Part 0: Calculation of currents," IEC 60909-0:2016, 2016.

[26] UNITROL 1005 User Manual, ABB, Aug. 2015.

[27] J. C. Das, "Arc flash hazard calculations in lv and mv dc systems part 2: Analysis," IEEE Transactions on Industry Applications, vol. 50, no. 3 , pp. 1698-1705, May. 2014. 


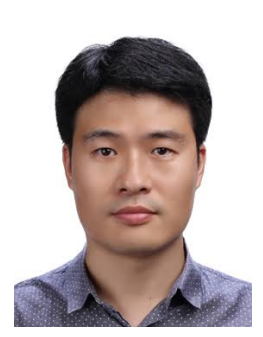

Seongil Kim (S'18) received the B.S. and M.S. degrees in electrical engineering from Hanyang University, Ansan and Seoul, Republic of Korea, in 2005 and 2007, respectively.

From 2007 to 2017, he was a Senior Researcher with Hyundai Heavy Industries Research Centre, Yongin, Republic of Korea, working on high voltage and power system engineering. Since 2017, he has been a Senior Researcher with Hyundai Electric and Energy Systems Research Centre, Yongin, Republic of Korea, working on the protection coordination of dc power systems. In 2017, he joined the Power Electronics Laboratory of Ecole Polytechnique Fédérale de Lausanne (EPFL), Lausanne, Switzerland as a FullTime Doctoral Assistant, working toward the Ph.D. degree. His current research interests include the areas of design, modeling and protection of dc power systems.

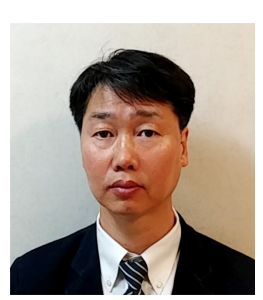

Soo-Nam Kim received the B.S., M.S., and Ph.D. degrees in electrical engineering from Hanyang University, Ansan and Seoul, Republic of Korea, in 1996, 1998 and 2003, respectively.

From 2003 to 2017, he was a Head Researcher with Hyundai Heavy Industries Research Centre, Yongin, Republic of Korea, working on power system engineering for various areas. Since 2017, he has been a Senior Researcher with Hyundai Electric and Energy Systems Research Centre, Yongin, Republic of Korea, working on switchgear development for ships and smart grids. He is currently leading the Future Power Grid Research Department of Hyundai Electric and Energy Systems Research Centre. His current research interests include the areas of design and control of eco-friendly grids for ships, buildings and cities.

Dr. Kim was a recipient of the Minister's Award for Smart Grid, Republic of Korea, as a Meritorious Person, in 2012.

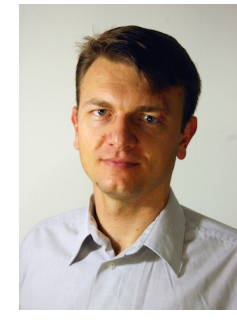

Drazen Dujic (S'03-M'09-SM'12) received the Dipl. -Ing. and M.Sc. degrees from the University of Novi Sad, Novi Sad, Serbia, in 2002 and 2005, respectively, and the Ph.D. degree from the Liverpool John Moores University, Liverpool, U.K., in 2008 , all in electrical engineering.

From 2002 to 2006, he was with the Department of Electrical Engineering, University of Novi Sad as a Research Assistant, and from 2006 to 2009 with Liverpool John Moores University as a Research Associate. From 2009 to 2013, he was with ABB Corporate Research Centre, Switzerland, as a Principal Scientist working on the power electronics projects spanning the range from low-voltage/power switched-mode power supply (SMPS) in below kilowatt range to medium voltage high-power converters in a megawatt range. From 2013 to 2014, he was with ABB Medium Voltage Drives, Turgi, Switzerland, as a R\&D Platform Manager, responsible for ABB's largest integrated gate-commutated thyristor (IGCT) based medium voltage drive ACS6000. He is currently with École Polytechnique Fédérale de Lausanne EPFL, Lausanne, Switzerland, as an Assistant Professor in Electrical Engineering and the Director of the Power Electronics Laboratory. He has authored or coauthored more than 150 scientific publications and has filed 14 patents. His current research interests include the areas of design and control of advanced high-power electronics systems and high performance drives.

Dr. Dujic is an Associate Editor for the IEEE Transactions on Industrial Electronics, IEEE Transaction on Power Electronics, and IET Electric Power Applications. He is the recipient of the First Prize Paper Award by the Electric Machines Committee of the IEEE Industrial Electronics Society at IECON, in 2007. He was the recipient of the european power electronics and drives association (EPE) Outstanding Service Award in 2018, and the Isao Takahashi Power Electronics Award in 2014, for outstanding achievement in power electronics. 